weather, it is equally important that the crop should not be so advanced that it emerges from the state of hardness before winter is over. Whether or not a plant is in the state that it can acquire or retain hardiness, cannot be judged by external appearance ; it is governed more by the stage of development than by state of growth.

In Great Britain, capacity to withstand water logging is a more important aspect of winter hardiness than frost resistance, and it is interesting to note from these contributions that 'hardening' increases resistance to water-logging as well as to frost, and that the curves of both were similar from the time of sowing throughout the winter.

Moshkov makes an interesting contribution on photoperiodism and hardiness, showing how plants introduced from regions of comparatively short daylength display a lowered resistance to frost when grown in regions with a greater length of day, such as near Lenungrad; the resistance is restored if the plants are shaded for some hours daily in such places, thus artificially shortening the day. The author is of opinion that plants are not so winter hardy when grown in places having a day-length differing from that of the region where they grow in the wild state. This work will probably throw light on some im. portant problems connected with the introduction of strains of pasture plants from country to country, and help to explain the value of the indigenous strains.

In a study of the effects of a covering of snow, it is pointed out that the plants are killed if the layer is too thin or too thick. It has hitherto been assumed that the harmful effect of a deep layer of snow is due to the exclusion of air ; but the authors show that it is caused by the exhaustion of the carbohydrates in the leaves and nodes, followed by a breakdown of proteins, and the subsequent attack of the weakened plants by 'snow mould'.

\title{
Metric System for Maps
}

$\mathrm{W}^{\mathrm{s}}$ $E$ have received a copy of the memorandum submitted by the Council of the Decimal Association to the Departmental Committee on the Ordnance Survey, appointed by the Minister of Agriculture and Fisheries, now sitting. The memorandum urges the adoption of the metric system for British maps.

The Association is naturally strongly in favour of the suggestion of the Director-General of the Ordnance Survey that a metric grid for maps of Great Britain would be preferable to a yard grid (see NATURE, February 1, p. 196). It also directs attention to the want of simplicity which exists among the present scales of maps. Of the eight different scales, only three are simple ratios to the actual. The Association agrees with the Director-General that if a grid system is adopted there are great advantages in having map scales exact multiples of one another.

In the accompanying table the existing Ordnance Survey scales are contrasted with the scales which it is suggested should replace them.

"It will be seen," the memorandum remarks, "that, with one exception, there is only a negligible difference of ratio between the existing and the suggested improved scales." Whether these changes could be brought about or not must largely depend on being able to educate the public to appreciate the advantages of the metric system. The Ministry of Transport might assist by having the distances on road finger-posts shown in kilometres, in brackets, after the present mileage figures. By this means the numerous map and road users could readily be reached.

\begin{tabular}{|c|c|c|c|}
\hline \multicolumn{2}{|c|}{ Suggested Natural Scale } & \multicolumn{2}{|c|}{ Scales of Existing Maps } \\
\hline Denomination & Ratio & Inches to mile & Ratio \\
\hline 1 & $1,000,000$ & $\overline{15} 7 \overline{3} \overline{2}$ & $1,000,000$ \\
\hline 2 & 500,000 & 10 & 633,600 \\
\hline 4 & 250,000 & 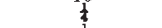 & 233,440 \\
\hline 8 & 125,000 & & 126,720 \\
\hline 16 & 62,500 & 1 & 63,360 \\
\hline 100 & 10,000 & 6 & 10,560 \\
\hline 400 & 2,500 & 25,344 & 2,500 \\
\hline 800 & 1,250 & 50,688 & 1,250 \\
\hline
\end{tabular}

Since the chief reference to the Departmental Committee is concerned with the revision of the Ordnance maps, it would appear to be a favourable opportunity, which may not occur again, for a serious consideration of the adoption of the metric system, now used in every Continental country. At the same time, a simplification of the scales could be taken in hand. Anyhow, nothing, we suggest, should be done to hamper the eventual adoption of the metric system, if it cannot be introduced at present.

\section{Design of Cargo Steamers}

$\mathrm{I}^{\mathrm{N}}$ the aftermath of the Great War, probably no branch of activity suffered so much disorganisation as that of shipbuilding. To make good the deficiencies of the moment, standard ships were hurriedly built with little or no relation to the particular work which each would have to do, and with inadequate attention to other details of design. The lean years which followed made the times difficult even for the most efficient of fleets, and, without any foundation on which to build up a post-War policy, the business of shipbuilding has been in much the same plight as a ship the steering gear of which has broken down.

From this unsatisfactory condition there is now some prospect of release, and in a paper entitled "New Cargo Steamers: Efficiency Problems" read before the North East Coast Institution of Engineers and Shipbuilders on March 6, Mr. J. Leslie Batey discusses the question of obsolescence and its bearing on the probable demand for new tonnage. A chart showing tonnage under construction in the United Kingdom since 1911 and the corresponding figure 